ORIGINAL ARTICLE

\title{
The influence of occupational exposure to pesticides, polycyclic aromatic hydrocarbons, diesel exhaust, metal dust, metal fumes, and mineral oil on prostate cancer: a prospective cohort study
}

\author{
D Boers, M P A Zeegers, G M Swaen, IJ Kant, P A van den Brandt
}

Occup Environ Med 2005;62:531-537. doi: 10.1136/oem.2004.018622

See end of article for authors' affiliations

Correspondence to: Ms D Boers, Maastricht University, Department of Epidemiology, PO Box 616, 6200 MD Maastricht, Netherlands; daisy.boers@ epid.unimaas.nl

Accepted 4 March 2005

\begin{abstract}
Aims: To investigate the relation between exposure to pesticides, polycyclic aromatic hydrocarbons (PAHs), diesel exhaust, metal dust, metal fumes, and mineral oil in relation to prostate cancer incidence in a large prospective study.

Methods: This cohort study was conducted among 58279 men in the Netherlands. In September 1986, cohort members (55-69 years) completed a self-administered questionnaire on potential cancer risk factors, including job history. Follow up for prostate cancer incidence was established by linkage to cancer registries until December 1995 (9.3 years of follow up). The analyses included 1386 cases of prostate cancer and 2335 subcohort members. A blinded case-by-case expert exposure assessment was carried out to assign cases and subcohort members a cumulative probability of exposure for each potential carcinogenic exposure.

Results: In multivariate analyses there was a significant negative association for pesticides (RR 0.60; $95 \%$ $\mathrm{Cl} 0.37$ to 0.95 ) when comparing the highest tertile of exposure to pesticides with no exposure. No association was found for occupational exposure to PAHs (RR $0.75 ; 95 \% \mathrm{Cl} 0.42$ to 1.31 ), diesel exhaust ( $R R 0.81 ; 95 \% \mathrm{Cl} 0.62$ to 1.06 ), metal dust (RR 1.01; $95 \% \mathrm{Cl} 0.72$ to 1.40 ), metal fumes (RR $1.11 ; 95 \% \mathrm{Cl}$ 0.80 to 1.54 ), or mineral oil (RR $0.99 ; 95 \% \mathrm{Cl} 0.66$ to 1.48 ) when comparing the highest tertile of exposure with no exposure. In subgroup analysis, with respect to tumour invasiveness and morphology, null results were found for occupational exposure to pesticides, $\mathrm{PAH}$, diesel exhaust, metal dust, metal fumes, and mineral oil.

Conclusions: These results suggest a negative association between occupational exposure to pesticides and prostate cancer. For other carcinogenic exposures results suggest no association between occupational exposure to $\mathrm{PAHs}$, diesel exhaust, metal dust, metal fumes, or mineral oil and prostate cancer.
\end{abstract}

Dostate cancer is the most frequently diagnosed malignancy among men in the Netherlands and other Western countries. ${ }^{12}$ Even after accounting for the effect of screening for prostate cancer, the age adjusted incidence is still increasing. ${ }^{12}$ This increasing incidence calls for research into the aetiology of this disease. However, despite many epidemiological studies, little is known about the aetiology of prostate cancer. Well known risk factors include age, ${ }^{34}$ race, $^{35}$ and family history of prostate cancer. ${ }^{67}$ Also diet, ${ }^{8-10}$ hormones, ${ }^{311}$ physical activity, ${ }^{12}{ }^{13}$ and occupation ${ }^{14-16}$ may influence prostate cancer risk. Consumption of meat may increase the risk of prostate cancer. ${ }^{910}{ }^{17}$ Some other studies indicate that consumption of fruit and/or vegetables might reduce the risk of prostate cancer, however results remain inconclusive. ${ }^{18}$

A wide variety of occupations in relation to prostate cancer have been investigated, mostly in case-control studies, ${ }^{15}{ }^{19-22}$ and also in the Netherlands Cohort Study. ${ }^{23}$

Exposures reported to be associated with prostate cancer are pesticides (especially herbicides), ${ }^{15} 19$ 24-30 cadmium, ${ }^{19} 2031$ aluminium, ${ }^{15}{ }^{19}$ polycyclic aromatic hydrocarbons, ${ }^{15} 3233$ engine emissions (particularly diesel exhaust), ${ }^{15} 203334$ and mineral oil. ${ }^{34-36}$ However, studies on occupational exposure to these substances and prostate cancer are sparse, especially studies on mineral oil, metals, polycyclic aromatic hydrocarbons (PAHs), or diesel exhaust. For pesticides and herbicides, there is some evidence of an association with prostate cancer. ${ }^{14}$ Use of some pesticides among farmers or pesticide applicators has been associated with prostate cancer in some studies. ${ }^{15} 1924253738$ Some of these also investigated separate types of pesticides. ${ }^{25}$ Several pesticides and herbicides are organochlorines. It has been hypothesised that certain organochlorines and other oestrogen-like compounds can induce adverse effects through modulation of various physiological or biochemical pathways. ${ }^{14}$

Only a few studies have examined the association between PAH compounds and prostate cancer. These studies showed excess risks. ${ }^{15233}$ There is also some indication of excess risks in occupations with potential exposure to PAHs like firefighters, ${ }^{21-23} 3940$ foundry and coke oven workers, ${ }^{16}$ chimney sweeps, and railway workers. ${ }^{21}{ }^{22}$ Likewise, only a few studies have examined the association between diesel exhaust and prostate cancer. Moreover, most studies have investigated exposure to engine exhaust in general. In most of these studies, ${ }^{15} 203334$ but not all, ${ }^{19}$ the authors have reported an excess risk for prostate cancer. Also excess risk for prostate cancer has been found among workers exposed to diesel exhaust such as truck drivers, ${ }^{21}{ }^{22}{ }^{41}$ bus drivers, ${ }^{21}$ or motor vehicle manufacturers. ${ }^{42}{ }^{43}$ Some of the compounds in diesel exhaust and some PAHs have antioestrogenic effects that may promote the growth of prostate cancer cells. ${ }^{14}$ 


\section{Main message}

- Results suggest that occupational exposure to pesticides, PAHs, diesel exhaust, metal dust, metal fumes, and mineral oil, do not play a role in the development of prostate cancer.

Furthermore, very few studies have examined the association between some metals and prostate cancer. The few studies that analysed specific exposures, provided some evidence for associations with some specific metal dusts and metalworking fluids like mineral oil. ${ }^{14}{ }^{44}$ And some studies, ${ }^{19} 20$ but not all $^{31}$ reported excess risks for workers exposed to cadmium. In a review, investigating the association between metal workers and prostate cancer, most studies reported an excess risk. ${ }^{44}$ But the literature provides too little information for firm conclusions about the relation between exposure to specific metals or metallic compounds and prostate cancer risk. Few studies investigating the risk of prostate cancer in metal workers reported mineral oils as a risk factor. Some studies, investigating the association between mineral oil and prostate cancer, have reported an increased risk for prostate cancer, ${ }^{34}$ and some have not. ${ }^{194546}$

In summary, there is still uncertainty about the possible association between the exposures mentioned above and the risk for prostate cancer.

In this study we will examine the association between occupational exposure to pesticides, polycyclic aromatic hydrocarbons (PAHs), diesel exhaust, metal dust, metal fumes, or mineral oil and prostate cancer within a large prospective cohort study in the Netherlands.

\section{METHODS \\ Study population}

The study design and data collection strategies have been described previously. ${ }^{47}$ In summary, the Netherlands Cohort Study (NLCS) is a prospective cohort study on diet, other lifestyle factors, sociodemographic characteristics, job history, and cancer risk, which started in 1986 among the general population in the Netherlands. The cohort includes 58279 men aged 55-69 years at baseline. The study population originated from 204 municipal population registries throughout the Netherlands. The case-cohort approach was used for data processing and analysis. ${ }^{48}$ Cases were enumerated from the entire cohort, while the accumulated person-years in the cohort were estimated from a subcohort sample. Following this approach, a subcohort of 2335 men was randomly sampled from the cohort after baseline measurement. The subcohort has been biennially followed up for information on vital status. No subcohort members were lost to follow up. A subcohort has the advantage of being cost effective compared to follow up of an entire cohort of this size.

\section{Case ascertainment and follow up}

Follow up for incident cancer was established by record linkage to all nine regional cancer registries in the Netherlands and PALGA, ${ }^{49}$ the Dutch database for pathology reports, leading to at least a $96 \%$ ascertainment of all incident cancers. ${ }^{49}{ }^{50}$ The presented analysis was restricted to 9.3 years of follow up, from September 1986 to December 1995.

Prevalent cases, other than skin cancer, were excluded. This led to a total of 2335 male subcohort members and 1386 cases with microscopically confirmed incident prostate cancer. Among the cases 526 men were diagnosed with localised prostate cancer, and 453 subjects were diagnosed

\section{Policy implication}

- Further specific investigations are necessary, since both positive and negative results have been reported by studies.

with advanced prostate cancer; the remaining subjects had an unknown tumour grade.

\section{Exposure assessment}

From all occupational exposures reported to be associated with prostate cancer, those that were selected were thought to have a sufficient high prevalence to yield relevant information. This restriction with regard to the prevalence of occupational exposure resulted in six relevant exposures: pesticides, PAHs, diesel exhaust, metal dust, metal fumes, and mineral oils. At baseline, the cohort members completed a self-administered questionnaire on potential risk factors for cancer. In this questionnaire, job history was covered by questions on job title, name of the company, type of company, time period, and information on type of products produced at the company. Information on job title, type of company, and type of product were coded according to the Dutch Occupational Classification System of the Central Bureau of the Statistics (CBS). ${ }^{51}$ Experts in the fields of occupational epidemiology (GMHS) and occupational hygiene (IJK) assessed separately the cumulative probability of carcinogenic exposures, blinded with respect to case or subcohort status.

Exposure assessment was conducted using information about company name, company type, product type, and employment period. ${ }^{52}$

Four exposure categories were defined: no exposure to the specific agent, possible exposure (probability of exposure estimated to be lower than 30\%), probable exposure (probability of exposure lies between $30 \%$ and 90\%), and nearly certain exposure (probability of exposure over $90 \%$ ). For a quantification of exposure a cumulative probability of exposure (CPE) was calculated, which combines information about the probability of exposure and the duration of exposure. A weight was assigned to each exposure category: no exposure, weight 0 ; possible exposure, weight 0.15 ; probable exposure, weight 0.6; and nearly certain exposure, weight 0.95 . Each weight corresponds to the midpoint of each exposure category. The CPE was calculated by multiplication of the weight given to each exposure category by the number of years exposed. Subsequently, for each person all weighted exposures were summed, for every carcinogen separately, and the exposed subjects were categorised in tertiles of exposure index.

\section{Statistical analysis}

Based on earlier studies on prostate cancer risk factors, the following variables were considered as potential confounders: age (years), first degree family history of prostate cancer (yes/ no), consumption of vegetables, fruit, meat, alcohol (g/day), smoking (ever/never), level of education (no education of primary school, lower vocational training, medium vocational training, high educational level (that is, university)), and physical activity (no, low, medium, or high). ${ }^{6-10} 185354$ Men with incomplete or inconsistent dietary data were excluded from analysis with dietary variables.

Incidence rate ratios and corresponding 95\% confidence intervals for prostate cancer were calculated in the age adjusted and multivariate case-cohort analysis with cumulative probability of exposure and dichotomous variables (exposed versus non-exposed), using the Cox proportional 
Table 1 Association between potential confounders and occupational exposure to pesticides, polycyclic aromatic hydrocarbons, diesel exhaust, metal dust, metal fumes and mineral oil and prostate cancer among subcohort members: the Netherlands Cohort Study 1986-1995

\begin{tabular}{|c|c|c|c|c|c|c|c|c|c|c|c|c|}
\hline \multirow[b]{2}{*}{ Exposure } & \multicolumn{2}{|c|}{ Pesticides } & \multicolumn{2}{|l|}{$\mathrm{PAH}^{*}$} & \multicolumn{2}{|c|}{ Diesel exhaust } & \multicolumn{2}{|c|}{ Metal dust } & \multicolumn{2}{|c|}{ Metal fumes } & \multicolumn{2}{|c|}{ Mineral oil } \\
\hline & $\begin{array}{l}\text { Never } \\
(n=59)\end{array}$ & $\begin{array}{l}\text { Ever } \\
(n=4)\end{array}$ & $\begin{array}{l}\text { Never } \\
(n=60)\end{array}$ & $\begin{array}{l}\text { Ever } \\
(n=2)\end{array}$ & $\begin{array}{l}\text { Never } \\
(n=45)\end{array}$ & $\begin{array}{l}\text { Ever } \\
(n=16)\end{array}$ & $\begin{array}{l}\text { Never } \\
(n=53)\end{array}$ & $\begin{array}{l}\text { Ever } \\
(n=9)\end{array}$ & $\begin{array}{l}\text { Never } \\
(n=53)\end{array}$ & $\begin{array}{l}\text { Ever } \\
(n=9)\end{array}$ & $\begin{array}{l}\text { Never } \\
(n=54)\end{array}$ & $\begin{array}{l}\text { Ever } \\
(n=8)\end{array}$ \\
\hline \multicolumn{13}{|l|}{ Potential confounders } \\
\hline Age (mean years) & 61.35 & 61.38 & 61.41 & 60.38 & 61.42 & 61.12 & 61.48 & 60.69 & 61.47 & 60.72 & 61.44 & 60.57 \\
\hline $\begin{array}{l}\text { Vegetablest (mean } \\
\text { g/day) }\end{array}$ & 190.2 & 182.9 & 188.1 & 206.4 & 187.9 & 193.3 & 187.9 & 196.4 & 187.9 & 197.1 & 188.0 & 199.0 \\
\hline Fruitt (mean g/day) & 150.6 & 157.1 & 150.6 & 159.4 & 149.7 & 156.1 & 151.2 & 152.8 & 151.4 & 152.5 & 150.9 & 153.8 \\
\hline Meat† (mean g/day) & 16.40 & 20.43 & 16.66 & 19.22 & 16.33 & 18.05 & 16.42 & 19.11 & 16.57 & 19.01 & 16.57 & 19.01 \\
\hline
\end{tabular}

*Polycyclic aromatic hydrocarbons.

$\ddagger$ Consumption of these foods.

hazards model, ${ }^{55}$ processed with the Stata statistical software package. ${ }^{56}$

The proportional hazards assumption was tested using the scaled Schoenfeld residuals. ${ }^{57}$ Two sided confidence limits are reported throughout the paper.

We have calculated subgroup analysis for occupational exposure to pesticides, PAHs, diesel exhaust, metal dust, metal fumes, or mineral oil, with respect to tumour invasiveness and morphology into localised prostate tumours (T0-2, M0: no evidence of primary tumour [T0], clinically unapparent tumour [Tl], or tumour confined within the prostate [T2], and no distant metastasis) or advanced prostate tumours (T3-4, M0 or Tl-4, Ml: tumour extending through the capsule [T3], fixed tumour or tumour invading

Table 2 Incidence rate ratios for prostate cancer $(n=1376)$ according to cumulative exposure to pesticides, polycyclic aromatic hydrocarbons, diesel exhaust, metal dust, metal fumes, and mineral oil in age adjusted and multivariate analysis: the Netherlands Cohort Study 1986-95

\begin{tabular}{|c|c|c|c|c|c|c|}
\hline Exposure & Cases (n) & $\begin{array}{l}\text { Person-years } \\
\text { (subcohort) }\end{array}$ & $\operatorname{RR}(95 \% \mathrm{Cl})^{*}$ & Cases (n) & $\begin{array}{l}\text { Person-years } \\
\text { (subcohort) }\end{array}$ & $\operatorname{RR}(95 \% \mathrm{Cl}) \dagger$ \\
\hline \multicolumn{7}{|l|}{ Pesticides } \\
\hline 0 (no exposure) & 1285 & 17996 & 1.00 (reference) & 1196 & 17129 & 1.00 (reference) \\
\hline 1 tertile (low) & 29 & 572 & $0.81(0.51$ to 1.28$)$ & 26 & 526 & $0.85(0.53$ to 1.36$)$ \\
\hline 2 tertile & 30 & 620 & $0.66(0.42$ to 1.04$)$ & 29 & 588 & $0.72(0.45$ to 1.14$)$ \\
\hline 3 tertile (high) & 32 & 635 & $0.64(0.41$ to 0.99$)$ & 27 & 570 & 0.60 (0.37 to 0.95$)$ \\
\hline$p$ trend & & & 0.006 & & & 0.008 \\
\hline \multicolumn{7}{|l|}{ PAH $\ddagger$} \\
\hline 0 (no exposure) & 1305 & 18524 & 1.00 (reference) & 1213 & 17586 & 1.00 (reference) \\
\hline 1 tertile (low) & 25 & 448 & $1.02(0.62$ to 1.69$)$ & 23 & 428 & $1.01(0.6070$ to 1.71$)$ \\
\hline 2 tertile & 26 & 452 & $0.91(0.55$ to 1.49$)$ & 23 & 442 & $0.76(0.44$ to 1.32$)$ \\
\hline 3 tertile (high) & 20 & 421 & $0.74(0.43$ to 1.28$)$ & 19 & 387 & $0.75(0.42$ to 1.31$)$ \\
\hline$p$ trend & & & 0.303 & & & 0.179 \\
\hline \multicolumn{7}{|l|}{ Diesel exhaust } \\
\hline 0 (no exposure) & 1065 & 14757 & 1.00 (reference) & 991 & 14011 & 1.00 (reference) \\
\hline 1 tertile (low) & 102 & 1738 & $0.88(0.68$ to 1.14$)$ & 93 & 1663 & $0.85(0.64$ to 1.11$)$ \\
\hline 2 tertile & 98 & 1582 & $0.92(0.70$ to 1.21$)$ & 90 & 1489 & $0.89(0.67$ to 1.20$)$ \\
\hline 3 tertile (high) & 102 & 1659 & $0.82(0.63$ to 1.06$)$ & 95 & 1582 & $0.81(0.62$ to 1.06$)$ \\
\hline$p$ trend & & & 0.101 & & & 0.067 \\
\hline \multicolumn{7}{|l|}{ Metal dust } \\
\hline 0 (no exposure) & 1168 & 16443 & 1.00 (reference) & 1082 & 15555 & 1.00 (reference) \\
\hline 1 tertile (low) & 66 & 1161 & $0.90(0.66$ to 1.24$)$ & 64 & 1133 & $0.88(0.64$ to 1.22$)$ \\
\hline 2 tertile & 70 & 1095 & 1.01 (0.74 to 1.38 ) & 64 & 1045 & $0.97(0.0 .70$ to 1.36$)$ \\
\hline 3 tertile (high) & 65 & 1081 & $0.98(0.71$ to 1.35$)$ & 64 & 1062 & $1.01(0.72$ to 1.40$)$ \\
\hline $\mathrm{p}$ trend & & & 0.837 & & & 0.789 \\
\hline \multicolumn{7}{|l|}{ Metal fumes } \\
\hline 0 (no exposure) & 1182 & 16659 & 1.00 (reference) & 1096 & 15777 & 1.00 (reference) \\
\hline 1 tertile (low) & 63 & 1124 & $0.88(0.64$ to 1.21$)$ & 60 & 1083 & $0.84(0.60$ to 1.17$)$ \\
\hline 2 tertile & 55 & 970 & $0.91(0.65$ to 1.29$)$ & 50 & 935 & $0.87(0.60$ to 1.25$)$ \\
\hline 3 tertile (high) & 69 & 1046 & $1.06(0.77$ to 1.47$)$ & 68 & 1018 & $1.11(0.80$ to 1.54$)$ \\
\hline $\mathrm{p}$ trend & & & 0.912 & & & 0.894 \\
\hline \multicolumn{7}{|l|}{ Mineral oil } \\
\hline 0 (no exposure) & 1242 & 17699 & 1.00 (reference) & 1151 & 16791 & 1.00 (reference) \\
\hline 1 tertile (low) & 45 & 729 & $1.02(0.70$ to 1.51$)$ & 42 & 686 & $1.01(0.68$ to 1.50$)$ \\
\hline 2 tertile & 43 & 723 & $1.02(0.69$ to 1.50$)$ & 42 & 711 & $1.01(0.68$ to 1.51$)$ \\
\hline 3 tertile (high) & 44 & 700 & $0.99(0.67$ to 1.47$)$ & 42 & 663 & $0.99(0.66$ to 1.48$)$ \\
\hline$p$ trend & & & 0.984 & & & 0.972 \\
\hline
\end{tabular}

*Incidence rate ratio adjusted for age with corresponding $95 \%$ confidence intervals.

†Incidence rate ratio adjusted for age, family history of prostate cancer, vegetable, fruit, and meat consumption, with corresponding $95 \%$ confidence intervals. $\ddagger$ Polycyclic aromatic hydrocarbons. 
Table 3 Incidence rate ratios for occupational exposure to pesticides, polycyclic aromatic hydrocarbons, diesel exhaust, metal dust, metal fumes, and mineral oil stratified for consumption of vegetables, fruit, and meat: the Netherlands Cohort Study 1986-95

\begin{tabular}{|c|c|c|c|c|c|c|}
\hline \multirow[b]{2}{*}{ Exposure* } & \multicolumn{2}{|l|}{ Vegetables (g/day) } & \multicolumn{2}{|l|}{ Fruit (g/day) } & \multicolumn{2}{|l|}{ Meat (g/day) } \\
\hline & Low $\leqslant 177.5 \dagger$ & High $>942.9 \dagger$ & Low $\leqslant 135.7 \dagger$ & High $>961.6 \dagger$ & Low $\leqslant 13.9 \dagger$ & High $>158.1 \dagger$ \\
\hline Pesticides & $0.80(0.58$ to 1.08$) \ddagger$ & $0.79(0.56$ to 1.10$)$ & $0.86(0.62$ to 1.19$)$ & 0.71 (0.51 to 0.98$)$ & $0.87(0.62$ to 1.24$)$ & $0.78(0.56$ to 1.08$)$ \\
\hline PAH§ & $0.88(0.59$ to 1.31$)$ & $0.99(0.71$ to 1.38$)$ & 1.26 (0.89 to 1.77$)$ & 0.77 (0.53 to 1.12 ) & $0.94(0.63$ to 1.40$)$ & $0.93(0.66$ to 1.32$)$ \\
\hline Diesel exhaust & $0.82(0.66$ to 1.00$)$ & $1.04(0.87$ to 1.24$)$ & 1.10 (0.90 to 1.33$)$ & 0.81 (0.67 to 0.98$)$ & $1.03(0.84$ to 1.26$)$ & $0.88(0.72$ to 1.07$)$ \\
\hline Metal dust & $0.92(0.71$ to 1.18$)$ & $1.06(0.86$ to 1.29$)$ & $1.00(0.79$ to 1.26$)$ & $1.00(0.81$ to 1.24$)$ & $1.23(0.98$ to 1.55$)$ & $0.90(0.71$ to 1.13$)$ \\
\hline Metal fumes & $0.96(0.74$ to 1.23$)$ & $1.01(0.82$ to 1.25$)$ & $0.96(0.75$ to 1.22$)$ & $1.02(0.82$ to 1.27$)$ & 1.20 (0.94 to 1.52$)$ & $0.91(0.72$ to 1.15$)$ \\
\hline Mineral oil & $0.98(0.73$ to 1.32$)$ & $1.14(0.91$ to 1.45$)$ & $1.00(0.77$ to 1.31$)$ & $1.16(0.90$ to 1.49$)$ & $1.26(0.96$ to 1.66$)$ & $0.99(0.75$ to 1.30$)$ \\
\hline
\end{tabular}

adjacent structures other than seminal vesicles [T4], and no distant metastasis [M0]; or any tumour [T0-4] with distant metastasis [Ml]), based on the TNM classification system. $^{54} 58$

\section{RESULTS}

The distribution of potential confounders was comparable between cases and subcohort members. In cases, a slightly higher consumption of vegetables $(51.38 \%$ versus $49.14 \%$ ) and fruit $(51.52 \%$ versus $48.11 \%)$ was reported, compared to subcohort members. Furthermore, family history of prostate cancer was more frequently reported by cases $(4.06 \%)$ than by subcohort members $(2.23 \%)$ (data not shown). The percentage of subjects exposed to pesticides, PAHs, diesel exhaust, metal dust, metal fumes, or mineral oil were approximately equally distributed among cases and subcohort members. However there were relatively more exposed subcohort members in the exposure tertiles than cases.

The distribution of some potential confounders, according to occupational exposure to pesticides, PAHs, diesel exhaust, metal dust, metal fumes, and mineral oil, appeared also comparable between cases and subcohort members and is presented in table 1. Most of the potential confounders are approximately equally distributed among men who were never or ever exposed to occupational carcinogens. However, men ever exposed to pesticides reported a relatively lower consumption (mean $182.9 \mathrm{~g} /$ day) of vegetables than men never exposed (mean $190.2 \mathrm{~g} /$ day) to pesticides. Furthermore, men ever exposed to pesticides presented a higher consumption of fruit (mean $157.1 \mathrm{~g} /$ day versus mean $150.6 \mathrm{~g} /$ day) and meat (mean $20.43 \mathrm{~g} /$ day versus mean $16.40 \mathrm{~g}$ /day). Likewise, men exposed to PAHs or diesel exhaust reported higher intakes of fruit than never exposed men. Persons ever exposed to PAHs (mean 206.4 g/day versus mean $188.1 \mathrm{~g} /$ day), metal dust, metal fumes, or mineral oil (mean $199.0 \mathrm{~g}$ /day versus mean $188.0 \mathrm{~g} /$ day) reported a higher consumption of vegetables than persons never exposed to these carcinogens (see table 1).

Table 2 shows the associations between cumulative probability of exposure (CPE) to agents and prostate cancer risk. The multivariate adjusted incidence rate ratio of prostate cancer was 0.60 (95\% CI 0.37 to 0.95 ) comparing high tertile of CPE to pesticides with no occupational exposure to pesticides ( $p$ trend $=0.008$ ). The age adjusted incidence rate ratio of prostate cancer was 0.64 (95\% CI 0.41 to 0.99 ) comparing the highest tertile of CPE to pesticides with no occupational exposure to pesticides. This negative trend was also significant; p trend was 0.006 . There appears to be little difference between age adjusted and multivariate adjusted analysis.
For occupational exposure to PAHs, diesel exhaust, metal dust, metal fumes, and mineral oil non-significant null results were noted of respectively 0.75 (95\% CI 0.42 to 1.31 ); 0.81 ( $95 \%$ CI 0.62 to 1.06 ); 1.01 ( $95 \%$ CI 0.72 to 1.40$) ; 1.11$ (95\% CI 0.80 to 1.54); and 0.99 (95\% CI 0.66 to 1.48 ) for highest tertile of CPE compared to no exposure (see table 2).

Table 3 shows incidence rate ratios for the association between prostate cancer and occupational exposure stratified for low or high consumption of vegetables, fruit, and meat. A statistically significant decreased risk has been found for men exposed to diesel exhaust with a high consumption of fruit (RR 0.81 ; 95\% CI 0.67 to 0.98 ) compared to no consumption of fruit. Also a decreased risk has been reported for exposure to metal dust and high meat consumption (RR 0.90; 95\% CI 0.72 to 1.13). Among men exposed to metal dust and low consumption of meat an increased risk for prostate cancer was found, but this was small and not statistically significant (RR 1.23; 95\% CI 0.98 to 1.55). Similarly an increased incidence rate ratio for low consumption of fruit and increased risk for prostate cancer was found among men exposed to PAHs, but this association did not reach statistical significance (RR 1.26; 95\% CI 0.89 to 1.77). Additionally, we found an increased incidence rate ratio for prostate cancer for the combination of low consumption of meat and exposure to mineral oils, which also did not reach statistical significance either (RR 1.26; 95\% CI 0.96 to 1.66) (table 3). Significant interactions were reported for the association between exposure to diesel exhaust and consumption of fruit $(p=0.02)$ or vegetables $(p=0.00)$, and for exposure to metal dust and consumption of meat $(\mathrm{p}=0.03)$.

We also carried out age adjusted subgroup analyses, with respect to tumour invasiveness and morphology (localised or advanced prostate cancer) (table 4). Results do not suggest any association between weighted exposures to occupational carcinogens and localised or advanced prostate cancer. For any weighted exposure to pesticides we noted an age adjusted rate ratio of 0.83 (95\% CI 0.60 to 1.15 ) for localised prostate cancer and 0.81 (95\% CI 0.57 to 1.15 ) for advanced prostate cancer. For weighted duration of exposure to the other carcinogens we also found non-significant null associations between any exposure and risk for localised or advanced prostate cancer (see table 4).

\section{DISCUSSION}

In this study we have examined the association between six occupational exposures and the incidence of prostate cancer. The results suggest no association between exposure to occupational exposures and prostate cancer. Subgroup analyses showed null results for occupational exposure to pesticides, PAH, diesel exhaust, metal dust, metal fumes, or mineral oil and localised or advanced prostate cancer. In a 
study by Elghany and colleagues, ${ }^{20}$ the researchers also made a distinction between all tumours and aggressive tumours. The results by Elghany et al support our reported null findings for exposure to metal dust or fumes and localised or advanced prostate cancer.

Excesses in risk have been found in most, ${ }^{15} 2425293759$ but not all ${ }^{60}$ studies investigating the relation between exposure to pesticides and prostate cancer. However, there are many different pesticides and most studies, including ours, have not analysed specific compounds. ${ }^{15}$ Some other studies have reported excess risk among farmers or herbicide applicators. ${ }^{26-29}$ Yet, farmers perform a wide variety of tasks, and are therefore exposed to numerous potential carcinogenic substances like solvents, fuels and oils, pesticides, and more. Occupations with exposure to pesticides are (mostly) farmers, gardeners, and pesticide applicators. In this study we have reported a slight inverse association for weighted duration of exposure to pesticides and prostate cancer. Also, in our previous analyses, ${ }^{23}$ no association was found for farming and prostate cancer. Our results are consistent with these findings. Assuming there is an excess risk from certain pesticides, it is not surprising that results show inconsistency. Farming practices differ between countries or even regions, leading to differences in exposure. ${ }^{60}$ Furthermore, many studies have grouped farm owners and farm workers together. They should be treated as distinct groups, ${ }^{60}$ and additionally some studies have not sufficiently adjusted for potential confounders. Moreover, most studies, including our study, have not been able to take into account the use of protective equipment (for example, clothing, mask). This may influence the risk of prostate cancer for exposure for farmers, since not all farmers are actually exposed.

Additionally, the analysis of other occupational exposures like PAHs, diesel exhaust, metal dust, metal fumes, and mineral oil also suggested no association with prostate cancer in the multivariate analysis. All these occupational exposures are, like farmers, troubled with heterogeneity in exposure. Metalworkers are exposed to a wide variety of solvents, oils, lubricants, metal dust, or metal fumes. Excess risk among metalworkers might be contributed to several risk factors. ${ }^{44}$ Exposure to PAHs is usually in the form of exposure to particles with PAHs, which makes it difficult to investigate because subjects are exposed to mixtures of PAH compounds and other chemicals. The same applies to exposure to diesel exhaust. ${ }^{33}$ A limitation of our analysis is that we have not actually measured exposure to these carcinogens, but made an estimate of the exposure, based on job title, type of company, company name, type of product, and duration of employment. Furthermore, we had no information on types of pesticides or metals being used.

The quality of the exposure assessment strongly affects the outcome of the risk estimate ${ }^{61}$ and ideally includes both intensity and duration of the occupational exposure for each specific study subject. However, in large population based studies it is almost impossible to obtain this information. Moreover, in this type of study the range of jobs with potential exposures may be large and within given jobs there may be a great possible variation of exposures. This makes it even more difficult to identify a clear link between jobs and exposures, compared with industry based studies. ${ }^{62}$ Farmers in particular show extreme heterogeneity in occupational exposures. In our study the occupational history of the study participants was obtained through questionnaires, which did not allow an estimation of the actual exposure concentrations that were experienced in the past. The highest achievable was a retrospective exposure assessment in terms of probability of exposure. In general this can be obtained through a job exposure matrix (JEM) or a case-by-case expert assessment. We used the case-by-case expert assessment in this study. The main advantage of the method, compared with the use of a JEM, is that all the available information (job title, type and name of company, type of product, and time period) was used for the exposure assessment. ${ }^{62}$ Moreover, a JEM may produce greater non-differential misclassification than exposure assessment by experts, ${ }^{62}{ }^{63}$ because information obtained from a JEM is mistakenly taken to relate to individual exposure. ${ }^{63}$ In case-by-case expert assessment different measures for exposures are applied; this allows more control of heterogeneity. However, a case-by-case expert assessment may not be sufficient to control for extreme heterogeneity as seen among farmers. It is possible that we have overestimated pesticide exposure in this study, and that our results for pesticide exposure are possibly biased.

Table 4 Adjusted incidence rate ratios of prostate cancer for any exposure compared with no exposure to pesticides, polycyclic aromatic hydrocarbons, diesel exhaust, metal dust, metal fumes, and mineral oil, in subgroups of localised versus advanced prostate tumours: the Netherlands Cohort Study 1986-95

\begin{tabular}{|c|c|c|c|c|c|c|}
\hline Exposure & Cases (n) & PY* & Localised tumourst $(n=526)$ & Cases (n) & PY* & Advanced tumours $\ddagger(n=453)$ \\
\hline \multicolumn{7}{|l|}{ Pesticides } \\
\hline No exposure & 483 & 17996 & 1.00 (reference) & 417 & 17996 & 1.00 (reference) \\
\hline Any exposure & 41 & 1879 & $0.83(0.60$ to 1.15$) \S$ & 34 & 1879 & $0.81(0.57$ to 1.15$) \S$ \\
\hline \multicolumn{7}{|l|}{ PAHब } \\
\hline No exposure & 495 & 18524 & 1.00 (reference) & 431 & 18524 & 1.00 (reference) \\
\hline Any exposure & 29 & 1351 & $0.96(0.66$ to 1.40$) \S$ & 20 & 1351 & $0.75(0.47$ to 1.18$) \S$ \\
\hline \multicolumn{7}{|l|}{ Diesel exhaust } \\
\hline No exposure & 408 & 14757 & 1.00 (reference) & 346 & 14757 & 1.00 (reference) \\
\hline Any exposure & 116 & 5118 & $0.87(0.71$ to 1.07$) \S$ & 105 & 5118 & $0.93(0.75$ to 1.16$) \S$ \\
\hline \multicolumn{7}{|l|}{ Metal dust } \\
\hline No exposure & 450 & 16443 & 1.00 (reference) & 375 & 16443 & 1.00 (reference) \\
\hline Any exposure & 74 & 3432 & $0.91(0.71$ to 1.17$) \S$ & 76 & 3432 & $1.09(0.85$ to 1.39$) \S$ \\
\hline \multicolumn{7}{|l|}{ Metal fumes } \\
\hline No exposure & 451 & 16659 & 1.00 (reference) & 382 & 16659 & 1.00 (reference) \\
\hline Any exposure & 73 & 3216 & $0.97(0.75$ to 1.24$) \S$ & 69 & 3216 & $1.05(0.81$ to 1.36$) \S$ \\
\hline \multicolumn{7}{|l|}{ Mineral oil } \\
\hline No exposure & 471 & 17699 & 1.00 (reference) & 411 & 17699 & 1.00 (reference) \\
\hline Any exposure & 53 & 2176 & $1.07(0.80$ to 1.43$) \S$ & 40 & 2176 & $0.93(0.67$ to 1.29$) \S$ \\
\hline $\begin{array}{l}\text { *Person-years (su } \\
\text { †Localised tumou } \\
\text { †Advanced tumo } \\
\text { §Incidence rate r } \\
\text { - Polycyclic arom }\end{array}$ & $\begin{array}{l}\text {-T2 and } \\
3-T 4 \text { and } \\
\text { sted for a } \\
\text { carbons. }\end{array}$ & $\begin{array}{l}\text { or TO-T4 } \\
\text { ars) with }\end{array}$ & $\begin{array}{l}\text { M1. } \\
\text { sponding } 95 \% \text { confidence inter }\end{array}$ & & & \\
\hline
\end{tabular}


To incorporate the effect of duration of exposure, which appeared to be essential in evaluation of exposures to carcinogenic agents, we calculated a cumulative probability of exposure, for the six carcinogens separately.

However, there are no criteria for determination of exposure in a case-by-case expert assessment, and the exposure assessment is affected by the learning phenomenon of the expert(s). To improve reliability we used a two stage exposure assessment in which two experts, blinded with respect to disease status, assessed the exposure. Disagreements were solved through consensus meetings. ${ }^{52}$

Furthermore, the same experts have implicated the caseby-case expert exposure assessment before using data from the same cohort. ${ }^{52}{ }^{64}$ In these investigations researchers have reported increased risks ${ }^{52}{ }^{64}$ for exposure to chemical carcinogens and cancer. Therefore, our null associations could also indicate that there is no association between occupational exposures and prostate cancer.

Epidemiological evidence on occupational exposure and prostate cancer, mostly, has been derived from either job titles (through a JEM) ${ }^{16} 20-2227$ or self-assessed exposures to certain occupational agents. ${ }^{19} 59$ Self-assessment of occupational exposure is considered inadequate since chemical knowledge of study subjects in general may not be sufficient to recall substance specific or duration specific occupational exposure. Only a few other studies have conducted an expert exposure assessment, ${ }^{154}$ as in our study. An important advantage of our study is that we were able to adjust for potential confounding factors by the means of data on nutrition, physical activity, alcohol use, and smoking, and that these data were collected prior to the diagnosis of prostate cancer. This approach essentially eliminates the likelihood of recall bias and has the advantage that the effect of non-occupational risk factors could be eliminated. Furthermore, we carried out a cohort study, which is less vulnerable for bias than a case-control study, for instance.

Our results are not supportive of associations between the investigated occupational exposures and prostate cancer, outside of exposure to pesticides. We noted a significant negative association for exposure to pesticides in the multivariate analysis. However, these results are possibly biased. Both positive and negative results have been reported for occupational exposure and prostate cancer, therefore more specific research is needed. In these future studies more detailed information on exposure (or potential confounders) is needed, and also information on protective measurements while working with the substances.

\section{ACKNOWLEDGEMENTS}

We are indebted to the participants of this study and further wish to thank the cancer registries (IKA, IKL, IKMN, IKN, IKO, IKR, IKST, IKW, IKZ, and VIKC), and the Netherlands nationwide registry of pathology (PALGA). We also thank Dr A Volovics and Dr A Kester for statistical advice; Dr L Schouten, $\mathrm{S}$ van de Crommert, H Brants, J Nelissen, C de Zwart, M Moll, W van Dijk, M Jansen, and A Pisters for assistance; and $\mathrm{H}$ van Montfort, $\mathrm{T}$ van Moergastel, $\mathrm{L}$ van den Bosch, and R Schmeitz for programming assistance.

\section{Authors' affiliations \\ D Boers, M P A Zeegers, G M Swaen, IJ Kant, P A van den Brandt, Department of Epidemiology, Maastricht University, Netherlands}

Funding: this study was financially supported by the Dutch Cancer Association

Competing interests: none declared

\section{REFERENCES}

1 Van Dijck JAAM, Coebergh JWW, Siesling S, et al. Trends of cancer in the Netherlands 1989-1998. Utrecht: Vereniging van Integrale Kankercentra, 2002.
2 Hsing AW, Devesa SS. Trends and patterns of prostate cancer: What do they suggest? Epidemiol Rev 2001;23:3-13.

3 Henderson BE, Feigelson HS. Hormonal carcinogenesis. Carcinogenesis 2000;21:427-33.

4 Van Barneveld TA, Horenblas S, Coebergh JWW, et al. Welke factoren beïnvloeden de kans op prostaatkanker? [Which factors influence the risk of prostate cancer?]. In, Volksgezondheid Toekomst Verkenning, Nationaal Kompas Volksgezondheid Bilthoven, RIVM, 2001

5 Mettlin C. Recent developments in the epidemiology of prostate cancer. Eur J Cancer 1997;33:340-7.

6 Zeegers MP, Jellema A, Ostrer $\mathrm{H}$. Empiric risk of prostate carcinoma for relatives of patients with prostate carcinoma: a meta-analysis. Cancer 2003;97:1894-903.

7 Whittemore AS, Wu AH, Kolonel LN, et al. Family history and prostate cancer risk in black, white, and Asian men in the United States and Canada. Am J Epidemiol 1995; 141:732-40.

8 Meyer JP, Gillatt DA. Can diet affect prostate cancer? BJU Int 2002;89:250-4.

9 Shirai T, Asamoto M, Takahashi S, et al. Diet and prostate cancer. Toxicology 2002; 181-2:89-94.

10 Chan JM, Stampfer MJ, Giovannucci EL. What causes prostate cancer? A brief summary of the epidemiology. Cancer Biology 1998;8:263-73.

11 Hsing AW, Reichardt JK, Stanczyk FZ. Hormones and prostate cancer: current perspectives and future directions. Prostate 2002;52:213-35.

12 Bairati I, Larouche R, Meyer F, et al. Lifetime occupational physical activity and incidental prostate cancer (Canada). Cancer Causes Control 2000;11:759-64.

13 Lee I, Sesso HD, Chen J, et al. Does physical activity play a role in the prevention of prostate cancer. Epidemiol Rev 2001;23:132-7.

14 Parent ME, Siemiatycki J. Occupation and prostate cancer. Epidemiol Rev $2001 ; 23: 138-43$

15 Aronson KJ, Siemiatycki J, Dewar R, et al. Occupational risk factors for prostate cancer: results from a case-control study in Montreal, Quebec, Canada. Am J Epidemiol 1996;143:363-73.

16 Sharma Wagner S, Chokkalingam AP, Malker HS, et al. Occupation and prostate cancer risk in Sweden. J Occup Environ Med 2000;42:517-25.

17 Gallagher RP, Fleshner N. Prostate cancer: 3. Individual risk factors. CMAJ 1998; 159:807-13.

18 Schuurman AG, Goldbohm RA, Dorant E, et al. Vegetable and fruit consumption and prostate cancer risk: a cohort study in the Netherlands. Cancer Epidemiol Biomarkers Prev 1998;7:673-80.

19 van der Gulden JW, Kolk JJ, Verbeek AL. Work environment and prostate cancer risk. Prostate 1995;27:250-7.

20 Elghany NA, Schumacher MC, Slattery ML, et al. Occupation, cadmium exposure, and prostate cancer. Epidemiology 1990;1:107-15

21 Krstev S, Baris D, Stewart PA, et al. Risk for prostate cancer by occupation and industry: a 24-state death certificate study. Am J Ind Med 1998;34:413-20.

22 Krstev S, Baris D, Stewart P, et al. Occupational risk factors and prostate cancer in U.S. blacks and whites. Am J Ind Med 1998;34:421-30.

23 Zeegers MPA, Friesema IHM, Goldbohm RA, et al. A prospective study on occupation and prostate cancer risk. J Occup Environ Med 2004;46:271-9.

24 Fleming LE, Bean JA, Rudolph M, et al. Cancer incidence in a cohort of licensed pesticide applicators in Florida. J Occup Environ Med 1999;41:279-88.

25 Alavanja MC, Samanic C, Dosemeci M, et al. Use of agricultural pesticides and prostate cancer risk in the Agricultural Health Study cohort. Am J Epidemiol 2003;157:800-14.

26 Bueno de Mesquita HB, Doornbos G, Van der Kuip DA, et al. Occupational exposure to phenoxy herbicides and chlorophenols and cancer mortality in the Netherlands. Am J Ind Med 1993;23:289-300.

27 Hooiveld M, Heederik DJ, Kogevinas M, et al. Second follow-up of a Dutch cohort occupationally exposed to phenoxy herbicides, chlorophenols, and contaminants. Am J Epidemiol 1998;147:891-901.

28 MacLennan PA, Delzell E, Sathiakumar N, et al. Cancer incidence among triazine herbicide manufacturing workers. J Occup Environ Med 2002; 44:1048-58

29 Mills PK, Yang R. Prostate cancer risk in California farm workers. J Occup Environ Med 2003:45:249-58

30 Morrison HI, Wilkins K, Semenciw R, et al. Herbicides and cancer. J Natl Cancer Inst 1992;84:1866-74.

31 Waalkes MP. Cadmium carcinogenesis in review. J Inorg Biochem 2000;79:241-4.

32 Nadon L, Siemiatycki J, Dewar R, et al. Cancer risk due to occupational exposure to polycyclic aromatic hydrocarbons. Am J Ind Med 1995;28:303-24

33 Seidler A, Heiskel H, Bickeboller R, et al. Association between diesel exposure at work and prostate cancer. Scand J Work Environ Health 1998;24:486-94.

34 Siemiatycki J, Dewar R, Nadon L, et al. Associations between several sites of cancer and twelve petroleum-derived liquids. Results from a case-referent study in Montreal. Scand J Work Environ Health 1987;13:493-504.

35 Tolbert PE. Oils and cancer. Cancer Causes Control 1997;8:386-405.

36 Tolbert PE, Eisen EA, Pothier $\amalg$, et al. Mortality studies of machining-fluid exposure in the automobile industry II: Risks associated with specific fluid types. Scand J Work Environ Health 1992;18:351-60.

37 Settimi L, Masina A, Andrion A, et al. Prostate cancer and exposure to pesticides in agricultural settings. Int J Cancer 2003;104:458-61 .

38 Dich J, Wiklund K. Prostate cancer in pesticide applicators in Swedish agriculture. Prostate 1998;34:100-12.

$39 \mathrm{Ma} \mathrm{F}$, Lee DJ, Fleming LE, et al. Race-specific cancer mortality in US firefighters: 1984-1993. J Occup Environ Med 1998;40:1134-8. 
40 Demers PA, Checkoway $\mathrm{H}$, Vaughan $\mathrm{TL}$, et al. Cancer incidence among firefighters in Seattle and Tacoma, Washington (United States). Cancer Causes Control 1994;5:129-35.

41 Järvholm B, Silverman D. Lung cancer in heavy equipment operators and truck drivers with diesel exhaust exposure in the construction industry. Occup Environ Med 2003;60:516-20.

42 Delzell E, Brown DA, Matthews R. Mortality among hourly motor vehicle manufacturing workers. J Occup Environ Med 2003:45:813-30.

43 Brown DA, Delzell E. Motor vehicle manufacturing and prostate cancer. Am J Ind Med 2000;38:59-70.

44 van der Gulden JW. Metal workers and repairmen at risk for prostate cancer: a review. Prostate 1997;30:107-16.

45 Jarvholm B, Lavenius B. Mortality and cancer morbidity in workers exposed to cutting fluids. Arch Environ Health 1987;42:361-6.

46 Ritz B. Cancer mortality among workers exposed to chemicals during uranium processing. J Occup Environ Med 1999;41:556-66.

47 van den Brandt PA, Goldbohm RA, van 't Veer P, et al. A large-scale prospective cohort study on diet and cancer in the Netherlands. J Clin Epidemiol 1990:43:285-95

48 Prentice RL. A case-cohort design for epidemiologic cohort studies and disease prevention trials. Biometrika 1986;73:1-11.

49 Van den Brandt PA, Schouten $\sqcup$, Goldbohm RA, et al. Development of a record linkage protocol for use in the Dutch Cancer Registry for Epidemiological Research. Int J Epidemiol 1990;19:553-8.

50 Goldbohm RA, van den Brandt PA, Dorant E. Estimation of the coverage of Dutch municipalities by cancer registries and PALGA based on hospital discharge data. Tiidschr Soc Gezond 1994;72:80-4.

51 Centraal Bureau voor de Statistiek. Beroepenclassificatie 1984: lijst van benamingen per beroepencode. Voorburg: CBS, 1985.
52 Zeegers MP, Swaen GM, Kant I, et al. Occupational risk factors for male bladder cancer: results from a population based case cohort study in the Netherlands. Occup Environ Med 2001;58:590-6.

53 Schuurman AG, van den Brandt PA, Dorant E, et al. Association of energy and fat intake with prostate carcinoma risk. Cancer 1999;86:1019-27.

54 Schuurman AG, Zeegers MP, Goldbohm RA, et al. A case-cohort study on prostate cancer risk in relation to family history of prostate cancer. Epidemiology 1999; 10:192-5.

55 Cox D. Regression models and life-tables (with discussion). J R Stat Soc Ser B 1972;34:187-220

56 Cleves MA, Gould WW, Gutierrez RG. An introduction to survival analysis using Stata. Texas: Stata Press, 2002.

57 Schoenfeld D. partial residuals for the proportional hazards regression model. Biometrics 1982:69:239-41.

58 Murphy GP, Lawrence W, Lenhard RE. American Cancer Society textbook of clinical oncology, 2nd edn. Atlanta, GA: American Cancer Society, 1995.

59 Ritchie JM, Vial SL, Fuortes $\sqcup$, et al. Organochlorines and risk of prostate cancer. J Occup Environ Med 2003:45:692-702.

60 Van Der Gulden JW, Vogelzang PF. Farmers at risk for prostate cancer. Br J Urol 1996;77:6-14

61 Dosemeci M, Cocco P, Gomez M, et al. Effects of three features of a jobexposure matrix on risk estimates. Epidemiology 1994;5:124-7.

62 Bouyer J, Hemon D. Retrospective evaluation of occupational exposures in population-based case-control studies: general overview with special attention to job exposure matrices. Int J Epidemiol 1993;22(suppl 2):S57-64.

63 Bouyer J, Hemon D. Studying the performance of a job exposure matrix. Int J Epidemiol 1993;22(suppl 2):S65-71.

64 van Loon AJ, Kant IJ, Swaen GM, et al. Occupational exposure to carcinogens and risk of lung cancer: results from the Netherlands cohort study. Occupational Environ Med 1997;54:817-24.

\section{Call for papers}

11 th European Forum on Quality Improvement in Health Care 26-28 April 2006, Prague, Czech Republic

Deadline 30 September 2005.

For further information and to submit online go to: www.quality.bmipg.com 